\title{
KONTRIBUSI SELF EFFICACY DAN GAYA BELAJAR TERHADAP HASIL BELAJAR MATEMATIKA SISWA KELAS VII SMP NEGERI 52 BATAM
}

\author{
Rizki Oktavianti S ${ }^{* 1}$, Yessy Yusnita ${ }^{2}$ \\ ${ }^{1}$ Program Studi Pendidikan Matematika, FKIP, Universitas Riau Kepulauan, Batam \\ ${ }^{2}$ Program Studi Teknik Sipil, Fakultas Teknik Sipil, Institut Teknologi Padang, Padang \\ e-mail: riskiokt@yahoo.com
}

\begin{abstract}
ABSTRAK. Penelitian ini bertujuan untuk mengetahui: (1) Kontribusi self efficacy terhadap hasil belajar. (2) Kontribusi gaya belajar terhadap hasil belajar matematika. (3) kontribusi self efficacy dan gaya belajar terhadap hasil belajar matematika siswa kelas VII SMP Negeri 52 Batam Tahun Ajaran 2016/2017. Jenis penelitian yang digunakan adalah penelitian korelasional. Populasi dari penelitian ini adalah seluruh siswa kelas VII SMP Negeri 52 Batam yang berjumlah 223 siswa. Teknik sampling yang digunakan berjenis simpel random sampling dengan 144 siswa. Instrumen pengumpulan data berupa angket yang telah diuji validitas serta reabilitasnya. Teknik analisis untuk menguji hipotesisnya menggunakan rumus korelasi kendal tau dengan dibantu softwer SPSS versi 20. Berdasarkan hasil penelitian maka diperoleh: (1) Tidak terdapat hubungan self efficacy terhadap hasil belajar $(\tau=0,107)$ dengan hasil belajar sangat lemah $(1,15 \%)$. (2) Tidak terdapat gaya belajar terhadap hasil belajar $(\tau=$ $0,068)$ dengan hasil belajar sangat lemah $(0,46 \%)$. (3) Tidak terdapat hubungan antar self efficacy dan gaya belajar $(\tau=0,151)$ dengan hasil belajar sebesar $(2,29 \%)$.
\end{abstract}

Kata Kunci: self efficacy, gaya belajar dan hasil belajar matematika

\begin{abstract}
This study aims to find out: (1) The contribution of self efficacy of students toward mathematics learning outcomes. (2) The contribution of learning style of students toward mathematics learning outcomes. (3) The contribution of self efficacy and learning tyle of students toward mathematics learning outcomes students VII SMP Negeri 52 Batam Academic Year 2016/2017. This type of research is correlation study. The population of the research is all students VII grade SMP Negeri 52 Batam totaling 223 students. The sampling technique is sample random sampling with 144 students. Data collection instrument such as questionnaires that has been tested for validity and reliabillty. The analytical technique to test the hypothesis using correlation formula of tau with assisted softwer SPSS version 20. Based on the results of the study: (1) There is no relationship of self efficacy to learning outcomes $(\tau=0.107)$ with very weak learning results $(1.15 \%)$. (2) There is no learning style to learning result $(\tau=0,068)$ with very weak learning result $(0,46 \%)$. (3) There is no relation between self efficacy and learning style $(\tau=0,151)$ with learning result equal to $(2,29 \%)$.
\end{abstract}

Keywords: self efficacy, learning style and mathematics learning outcomes

\section{Pendahuluan}

Pendidikan merupakan proses yang dilakukan secara bertahap dan sistematis, mulai dari pendidikan dasar, menengah hingga Perguruan Tinggi. Pendidikan dilaksanakan dengan tujuan menjadikan seseorang lebih baik dan mengembangkan kemampuan yang ada untuk kehidupan, baik di masa sekarang maupun masa yang akan datang. Untuk itu perlunya dilakukan usaha terencana agar dapat membentuk sumber daya manusia yang berkualitas serta sesuai dengan tuntutan zaman. Peningkatan sumber daya manusia didukung oleh pemerintah, hal ini tertuang dalam Undang-Undang Tentang Sistem Pendidikan Nasional nomor 20 tahun 2003 yaitu pendidikan nasioanal dapat mengembangkan kemampuan, membentuk watak serta peradaban bangsa dengan tujuan untuk berkembangnya potensi peserta didik agar menjadi manusia yang beriman dan bertakwa kepada Tuhan Yang Maha Esa, berakhlak mulia, sehat, 
berilmu, cakap, kreatif, mandiri, dan menjadi warga negara yang demokratis serta bertanggung jawab.

Fungsi pendidikan nasional dapat dilihat dari proses pembelajaran di sekolah, maupun lembaga pendidikan formal lainnya. Selama belajar di sekolah siswa diwajibkan untuk mengikuti semua mata pelajaran yang ada di sekolah. Dalam hal ini siswa berperan sebagai subjek dalam dunia pendidikan. Salah satu mata pelajaran yang diberikan dijenjang pendidikan dasar maupun pendidikan menengah adalah matematika.

Matematika merupakan salah satu mata pelajaran yang dipelajari secara berkelanjutan serta dapat diaplikasikan dalam berbagai bidang kehidupan. Dilihat dari segi unsur-unsurnya, matematika dikenal sebagai ilmu yang terstruktur, sistematis dan terjalin dalam hubungan fungsional yang erat sehingga matematika membutuhkan konsentrasi berfikir dan ketekunan agar dapat menyelesaikan permasalahan yang berhubungan dengan matematika. Akan tetapi, matematika yang sistematis menjadi salah satu alasan sulitnya siswa memahami matematika serta menjadikan siswa tersebut kurang minat dalam mempelajari pelajaran tersebut. Kurangnya minat belajar ditandai dengan perilaku yang tidak bersemangat dalam mengikuti pelajaran, dikarenakan matematika sangat membutuhkan konsentrasi berfikir yang tinggi serta ketekunan.

Masalah yang sering timbul dalam proses pembelajaran adalah kurangnya self efficacy dan gaya belajar yang dimiliki siswa. Menurut (Panjares, 2006) self efficacy adalah keyakinan seseorang terhadap kemampuan mereka agar bisa berhasil mencapai tujuan. Sedangkan menurut (Bare, A.L.,Uda,G., 2014) gaya belajar merupakan cara termudah yang dimiliki oleh individu dalam menyerap, mengatur dan megelolah informasi yang diterima.

Berdasarkan observasi dan wawancara yang dilakukan di SMP Negeri 52 Batam masalah yang sering timbul mengenai self efficacy dalam proses pembelajaran adalah jika siswa menemukan soal yang berbeda dari contoh yang diberikan, siswa mudah menyerah untuk menyelesaikan soal tersebut. Menurut keterangan dari beberapa siswa, pelajaran matematika merupakan pelajaran yang sulit untuk dipahami, hal ini sering dikeluhkan oleh siswa kepada wali kelas, dan juga dibuktikan dengan nilai raport siswa yang menunjukan bahwa nilai matematika memang tergolong rendah. Keterangan yang diperoleh dari guru mata pelajaran matematika siswa kurang mempunyai semangat untuk mengikuti pelajaran matematika, hal ini dibuktikan dengan hasil raport yang kurang adanya peningkatan kearah yang lebih baik dan hasil ulangan harian juga kurang memuaskan, lebih lanjut menurut guru matematika, banyak siswa yang tidak semangat untuk belajar matematika, hal ini karena kurangnya kesadaran siswa akan pentingnya belajar dan apa yang harus dilakukan saat belajar, tidak mau usaha untuk lebih keras, tidak mempunyai kreativitas, kurangnya percaya diri dan kurang mempunyai sikap optimis. Selain itu terdapat juga siswa yang sibuk dengan urusan masing-masing saat proses belajar mengajar dan adanya siswa yang lebih senang belajar sendiri, dan terdapat siswa yang ribut di kelas pada saat proses belajar mengajar. Keterangan yang diperoleh dari guru mata pelajaran matematika siswa belum memahami gaya belajar masing-masing sehingga siswa belum dapat memaksimalkannya dalam proses belajar.

Selain dari hasil observasi dan wawancara peneliti juga menyebarkan angket simulasi kepada 36 orang siswa dengan 10 pertanyaan mengenai self efficacy dan gaya belajar yang dimiliki siswa. Adapun isi angket tersebut sebagai berikut. 
Tabel 1. Instrumen untuk Mengukur Self Efficacy dan Gaya Belajar

\begin{tabular}{|c|c|c|c|c|c|}
\hline \multirow{2}{*}{ No } & \multirow{2}{*}{ Peryataan } & \multicolumn{4}{|c|}{ Jawaban } \\
\hline & & SS & $\mathbf{S}$ & ts & sts \\
\hline 1. & Saya yakin dapat mengerjakan tugas yang sulit & & & & \\
\hline 2. & $\begin{array}{l}\text { Saya belajar lebih awal di rumah jika mendapatkan tugas } \\
\text { dari guru }\end{array}$ & & & & \\
\hline 3. & Saya malas mengerjakan pekerjaan rumah (PR) & & & & \\
\hline 4. & Saya bertanya pada guru bila menemukan soal yang sulit & & & & \\
\hline 5 . & $\begin{array}{l}\text { Saya mudah menyerah saat mengalami kesulitan dalam } \\
\text { belajar. }\end{array}$ & & & & \\
\hline 6. & $\begin{array}{l}\text { Sebelum berangkat ke sekolah, saya memperhatikan } \\
\text { kerapian baju sekolah saya. }\end{array}$ & & & & \\
\hline 7. & $\begin{array}{l}\text { Ketika belajar matematika saya lebih suka membaca materi } \\
\text { sendiri di rumah dibandingkan dijelaskan oleh guru di } \\
\text { sekolah }\end{array}$ & & & & \\
\hline 8. & $\begin{array}{l}\text { Saya tidak merasa terganggu ketika dalam memperhatikan } \\
\text { guru mengajar ada teman yang berbicara. }\end{array}$ & & & & \\
\hline 9. & Saya suka mendengarkan musik sambil belajar & & & & \\
\hline 10. & $\begin{array}{l}\text { Saya mudah mengerti pelajaran matematika dengan } \\
\text { menulis ulang catatan pelajaran saya dirumah. }\end{array}$ & & & & \\
\hline
\end{tabular}

Berdasarkan data yang diperoleh dari angket simulasi yang disebarkan ke pada 36 orang siswa maka di dapat derajat pencapaian bahwa $63,66 \%$ self efficacy dan $59,88 \%$ gaya dari perolehan derajat pencapain tersebut terlihat masih rendahnya hal ini diduga berpengaruh terhadap hasil belajar siswa. Adapun perolehan hasil belajar matematika siswa kelas VII SMP Negeri 52 Batam dapat dilihat dari Tabel 2 berikut.

Tabel 2. Perolehan Hasil Belajar Matematika Ulangan Tengah Semester (UTS) Semester 1 Tahun Ajaran 2016/2017

\begin{tabular}{cccccc}
\hline No & Kelas & $\begin{array}{c}\text { Jumlah } \\
\text { Siswa }\end{array}$ & $\begin{array}{c}\text { Jumlah yang } \\
\text { Tuntas }\end{array}$ & KKM & Ketuntasan (\%) \\
\hline 1 & VII-A & 45 & 18 & & 43,30 \\
2 & VII-B & 44 & 20 & & 48,88 \\
3 & VII-C & 45 & 23 & 75 & 52,31 \\
4 & VII-D & 44 & 15 & & 32,43 \\
5 & VII-E & 45 & 23 & & 52,31 \\
\hline
\end{tabular}

Sumber: Guru mata pelajaran matematika kelas VII SMP Negeri 52 Batam

Berdasarkan Tabel 2 di atas terlihat perolehan hasil belajar masih banyak siswa yang memperoleh nilai di bawah Kriteria Ketuntasan Minimum. Hal inilah yang membuat peneliti tertarik untuk meneliti seberapa besar kontribusi Self Efficacy dan Gaya Belajar terhadap hasil belajar siswa. Diharapkan dengan mengetahui "Kontribusi Self Efficacy dan Gaya Belajar 
Terhadap Hasil Belajar Matematika Siswa Kelas VII SMP Negeri 52 Batam Tahun Pelajaran 2016/2017' dapat menjadi tolak ukur bagi peneliti dan guru untuk mengetahui keyakinan diri siswa dan gaya belajar siswa khususnya pada pembelajaran matematika agar dapat berdampak positif terhadap hasil belajar matematika.

\section{Metode Penelitian}

Penelitian ini termasuk pendekatan kuantitatif dengan menggunakan desain korelasional. Penelitian ini dilaksanakan di SMP Negeri 52 Batam tahun pelajaran 2016/2017. Dalam penelitian ini yang menjadi variabel bebas adalah self efficacy $\left(\mathrm{X}_{1}\right)$ dan gaya belajar $\left(\mathrm{X}_{2}\right)$. Variabel terikat hasil belajar matematika (Y). Populasi dalam penelitian ini meliputi seluruh siswa kelas VII SMP Negeri 52 Batam Tahun Ajaran 2016/2017 yang berjumlah 223 orang siswa. Sedangkan untuk sampel penelitian ini peneliti menggunakan metode simpel random sampling.

Sementara itu instrumen yang digunakan dalam penelitian ini adalah angket. Menurut (Widoyoko, 2013) angket atau kuesioner merupakan metode pengumpulan data yang dilakukan dengan cara memberi kesepakatan pertanyaan atau pertanyaan tertulis kepada responden untuk diberikan respon sesuai dengan permintaan pengguna.

Indikator yang diambil peneliti dalam pembuatan angket untuk variabel self efficacy meliputi: (1) Magnitude; (2) Strength; dan (3) Generality. Sedangkan yang menjadi indikator gaya belajar meliputi: (1) visual; (2) auditori; (3) kinestik.

Pengujian validitas menggunakan validitas konstruk yang diperoleh dengan melakukan uji coba di SMP Negeri 32 Batam. Untuk mengetauhi kuesioner tersebut valid atau tidak dengan menggunakan rumus product moment. Sedangkan untuk reliabilitas dihitung menggunakan rumus alfa cronbach. Setelah instrument diuji coba dan dianalisis reliabilitasnya, diperoleh koefisien reliabilitas angket self efficacy sebesar 0,952 dan untuk angket gaya belajar sebesar 0,858 sehingga dapat disimpulkan bahwa instrument reliabel.

Untuk teknik analisis data, terlebih dahulu menggunakan uji normalitas uji yang digunakan untuk mengetahui bahwa sebaran data penelitian berdistribusi normal atau tidak. Pengujian normalitas menggambarkan bahwa sampel yang diambil berasal dari populasi yang berdistribusi secara normal (Kasmadi \& Nia, 2014). Uji normalitas pada penelitian ini menggunakan uji Kolmogorov Smirnov dibantu dengan SPSS Versi 20. Hasil uji normalitas ditunjukkan pada tabel 4 di bawah.

Tabel 3. Hasil Uji Normalitas

\begin{tabular}{cccccc}
\hline No. & Kelompok & sig & A & Keputusan & Ket. \\
\hline 1 & Self efficacy & 0,099 & 0,05 & Ho diterima & Tidak Normal \\
2 & Gaya belajar & 0,095 & 0,05 & Ho diterima & Tidak Normal \\
3 & Hasil belajar matematika & 0,013 & 0,05 & Ho diterima & Tidak Normal
\end{tabular}

Berdasarkan hasil Tabel 3 diperoleh hasil signifikansi (sig) pada kolmogrov smirnov untuk variabel self efficacy sebesar 0,099, variabel gaya belajar sebesar 0,095 dan variabel hasil belajar matematika sebesar 0,013. Dapat dinyatakan bahwa nilai self efficacy dan gaya belajar yang didapat dari hasil tabel uji kolmogrov smirnov lebih kecil dari 0,05 yang berarti data variabel self efficacy dan gaya belajar berdistribusi normal dan nilai data hasil belajar tidak berdistribusi normal. 
Berdasarkan hasil uji normalitas maka pengujian uji hipotesis pertama dan kedua menggunakan rumus Kendal Tau $(\tau)$ dengan dibantu software SPSS versi 20. Adapun rumus kendal tau $(\tau)$ sebagai berikut:

$$
\tau=\frac{\sum A-\sum B}{\frac{N(N-1)}{2}}
$$

Selanjutnya untuk mengetahui besar kecilnya konstribusi yang diberikan variabel $\mathrm{X}$ terhadap variabel $\mathrm{Y}$ adalah dengan rumus koefisien determinan $(\mathrm{KD})$ sebagai berikut

$$
\mathrm{KD}=\tau^{2} \times 100 \%
$$

Keterangan:

$\mathrm{KD}=$ Nilai koefisien determinan

$\mathrm{r} \quad=$ Nilai Koefisien korelasi

sedangkan untuk mencari koefisien korelasi berganda pada hipotesis 3 menggunakan rumus:

$$
r_{X_{1} X_{2} Y}=\sqrt{\frac{r_{X_{1} Y^{2}+} r_{X_{2} Y^{2}}-2 r_{X_{1} Y} r_{X_{2} Y} r_{X_{1} X_{2}}}{1-r_{X_{1} X_{2}}}}
$$

Keterangan:

$r_{x_{1} x_{2} y}=$ korelasi antara variabel $x_{1}$ dengan $x_{2}$ Secara bersama-sama dengan variabel $y$

$r_{x_{1} y} \quad=$ korelasi product moment antara $x_{1}$ dengan $y$

$r_{x_{2} y} \quad=$ korelasi product moment antara $x_{2}$ dengan $y$

$r_{x_{1} x_{2}}=$ korelasi product moment antara $x_{2}$ dengan $x_{2}$

Kemudian untuk menguji signifikansi koefisien korelasi berganda digunakan uji F:

$$
F_{\text {hitung }}=\frac{r^{2}{ }_{X_{1} X_{2} Y} / m}{\left(1-r^{2}{ }_{X_{1} X_{2} Y}\right) / n-m-1}
$$

Keterangan:

$\begin{array}{ll}\mathrm{n} & =\text { jumlah sampel } \\ \mathrm{r} & =\text { koefisien korelasi ganda } \\ \mathrm{m} & =\text { jumlah variabel bebas }\end{array}$

Kemudian untuk menentukan kontribusi atau besarnya sumbangan yang diberikan oleh variabel $X_{1}, X_{2}$, terhadap Y secara simultan (bersama-sama) dapat diketahui melalui rumus koefisien determinan (KD) sebagai berikut (Ridwan, 2012).

$$
\mathrm{KD}=\left(R_{X_{1} \cdot X_{2} \cdot Y}\right)^{2} \mathrm{X} 100 \%
$$

$\mathrm{KD}=$ Nilai koefisien determinan

$\mathrm{R}=$ Nilai koefisien korelasi berganda 
Sementara itu, untuk kategori besarnya nilai koefisien korelasi dapat dilihat pada Tabel 3 berikut.

Tabel 4. Interpretasi koefisien korelasi

\begin{tabular}{cc}
\hline Interval Koefisien & Tingkat Hubungan \\
\hline $0,00-0,199$ & Sangat Rendah \\
$0,20-0,399$ & Rendah \\
$0,40-0,599$ & Sedang \\
$0,60-0,799$ & Kuat \\
$0,80-1,000$ & Sangat Kuat \\
\hline
\end{tabular}

Sumber: Widoyoko (2012: 152)

\section{Hasil Penelitian dan Pembahasan}

Hasil penghitugan uji signifikan koefesien korelasi hipotesis dapat dilihat pada Tabel 5 berikut:

Tabel 5. Hasil penghitugan uji signifikan koefesien korelasi hipotesis

\begin{tabular}{ccccccc}
\hline Hipotesis & Variabel & $\mathbf{N}$ & $(\boldsymbol{\tau})$ & $\boldsymbol{Z}_{\text {hitung }}$ & $\boldsymbol{Z}_{\text {tabel }}$ & KD \\
\hline 1 & $X_{1} Y$ & 144 & 0,107 & 1,96 & 2,58 & 1,15 \\
2 & $X_{2} Y$ & & 0,068 & 1.24 & & 0,46 \\
\hline
\end{tabular}

Berdasarkan Tabel 5 didapatkan hasil koefesien korelasi antara variabel self efficacy $\left(\mathrm{X}_{1}\right)$ dan hasil belajar matematika (Y) 0,107 dan termasuk kategori hubungan yang sangat rendah $z_{\text {hitung }}>z_{\text {tabel }}$ yang berarti tidak terdapat hubungan yang signifikan. Gaya belajar $\left(\mathrm{X}_{2}\right)$ dan hasil belajar $(\mathrm{Y})$ adalah 0,068 termasuk kategori hubungan yang sangat rendah $z_{\text {hitung }}>z_{\text {tabel }}$ yang berarti tidak terdapat hubungan yang signifikan.

Dari hasil perhitungan hipotesis 1 dan 2, sudah dapat ditebak hasil perhitungan untuk uji hipotesis yang ke 3. Berikut disajikan hasil perhitungan untuk uji hipotesis 3 .

Tabel 6. Hasil perhitungan uji signifikansi koefisien korelasi ganda

\begin{tabular}{ccccccc}
\hline Hipotesis & Variabel & $\mathbf{N}$ & $(\boldsymbol{\tau})$ & $\boldsymbol{F}_{\text {hitung }}$ & $\boldsymbol{F}_{\text {tabel }}$ & KD \\
\hline 3 & $X_{1}, X_{2}, Y$ & 144 & 0,105 & 3,30 & 3,04 & 2,40 \\
\hline
\end{tabular}

Berdasarkan hasil perhitungan pada Tabel 6, diperoleh koefisien korelasi ganda antara variabel self efficacy $\left(\mathrm{X}_{1}\right)$ dan gaya belajar $\left(\mathrm{X}_{2}\right)$ dan hasil belajar $(\mathrm{Y})$ adalah 0,105 dan termasuk kategori hubungan yang sangat rendah dengan nilai $F_{\text {hitung }} \geq F_{\text {tabel }}$ yang berarti terdapat hubungan yang signifikan. Dari hasil di atas dapat disimpulkan bahwa tidak terdapat hubungan yang signifikan antara self efficacy dan gaya belajar antara siswa terhadap hasil belajar matematika kelas VII SMP Negeri 52 Batam.

Hasil penelitian juga diperoleh sesuai dengan pernyataan yang dikemukakan (Hutagulung, 2014) bahwa semakin baik self efficacy yang dimilki siswa maka hasil belajar matematika siswa juga akan semakin tinggi, self efficacy memilki hubungan yang kuat degan hasil belajar matematika. Ini sesuai dengan indikator angket yang digunakan, sebagai contoh yaitu berpandangan optimis dalam mengerjakan tugas merupakan indikator yang rendah 
sedangkan dan indikator yang tinggi adalah saya mudah menyerah saat mengalami kesulitan dalam belajar matematika. Jika siswa berpandangan optimis dalam mengerjakan tugas maka siswa tersebut akan membuat sejumlah rencana dan selalu berusaha dengan gigih agar tugas yang dikerjakannya dapat selesai dengan baik.

Konsep dari gaya belajar adalah diferensisasi individual dalam belajar yang berdasarkan cara yang dipilih oleh individual untuk dipakai pada fase yang berbeda dalam siklus belajar. (Bare, A.L.,Uda,G., et al, 2014) Tiap individu memiliki gaya belajar yang berbeda satu sama lain, ini disebabkan faktor pengalaman dan juga bergantung pada lingkungan. Pemakaian gaya belajar oleh individu sebenarnya merupakan sarana untuk memfasilitasi agar belajar dapat mencapai tujuannya maka setiap individu mempunyai cara tersendiri yang dipilih sesuai dengan dirinya. Sehingga perbedaaan gaya belajar yang dipilih individu menunjukan cara tercepat dan terbaik bagi setiap individu bisa menyerap sebuah informasi dari luar dirinya dan pada akhirnya dapat

\section{Kesimpulan}

Berdasarkan hasil penelitian yang telah dilakukan, maka dapat ditarik kesimpulan sebagai berikut:

1. Terdapat kontribusi antara self efficacy terhadap hasil belajar matematika siswa kelas VII SMP Negeri 52 Batam tahun pelajaran 2016/2017. Besar hubungan secara parsial adalah 0,107 dengan kontribusi 1,15\% dengan kategori kontribusi yang sangat rendah.

2. Terdapat kontribusi antara gaya belajar terhadap hasil belajar matematika siswa kelas VII SMP Negeri 52 Batam tahun pelajaran 2016/2017. Besar hubungan secara parsial adalah 0,68 dengan kontribusi $0,46 \%$ dengan kontribusi yang sangat rendah.

3. Terdapat kontribusi antara self efficacy dan gaya belajar secara bersama-sama terhadap hasil belajar matematika siswa kelas VII SMP Negeri 52 Batam tahun pelajaran 2016/2017. Besar hubungan secara simultan adalah 0,151 dengan kontribusi 2,29\%. Jadi berdasarkan tingkat korelasi dan kekuatan hubungan dapat disimpulkan bahwa self efficacy dan gaya beajar dengan hasil belajar memilki hubungan yang sangat rendah.

\section{Daftar Pustaka}

Bare, A.L.,Uda,G., et al. (2014). Pengaruh gaya belajar visual, audotorial, dan kinestik terhadap prestasi belajar siswa (Vol. 44). Retrieved from http: jurnal.untad.ac.id/jurnal/index.php/JEPMT/article/view/4321/2176

Hutagulung. (2014). Hubungan Self Efficacy dan Motivasi Belajar dengan Hasil Beljar Matematika siswa kelas XI IPS SMA NEGRI 5 BATAM Tahun Pelajaran 2013/2014. Universitas Riau Kepulauan, Batam: Universitas Riau Kepulauan, Batam.

Kasmadi \& Nia. (2014). Panduan Modern Penelitian Kuantitaif. Bandung: Alfabeta.

Panjares. (2006). Self efficacy During Childhood and Adolescence. Chapter 15. Retrieved from http://sites.education.uky.edu/motivation/files/2013/08/18464-SelfEfficacy_During_Childhood_and_AdolescenceImplications_for_Teachers_and_Parents.pdf

Ridwan. (2012). Pengaturan Statistika untuk Penelitian Pendidikan Sosial Komunikasi 
Oktavianti \& Yusnita; Kontribusi Self Efficacy Dan Gaya Belajar.....

Ekonomi, dan Bisnis. Bandung: Alfabeta.

Siregar, S. (2013). Metode Penelitian Kuantitatif: Dilengkapi Perbandingan Perhitungan Manual \& SPSS. jakarta: kencana.

Widoyoko, E. (2013). Teknik Penyusunan Instrument Penelitian. Yogyakarta: Pustaka Pelajar. 